\title{
Los niveles de indagación semántica: la sintagmática suboracional del léxico derivado*
}

\author{
Levels of semantic analysis: the sub-sentential \\ syntagmatics of the derived lexicon
}

MARÍA TADEA DíAz HoRMigO

RECIBIDO:10 DE JULIO DE 2016

Grupo de investigación "Semaínein"

Instituto Universitario de Investigación en Lingüística Aplicada

Área de Lingüística General

Departamento de Filología

Facultad de Filosofía y Letras

Universidad de Cádiz

Avda. Gómez Ulla, $n^{0} 1$

11003 Cádiz-España

tadea.diaz@uca.es

Resumen: La indagación de las dimensiones paradigmática y sintagmática del léxico derivado contribuye a mostrar la interfaz de las (sub)disciplinas de la semántica morfológica, la semántica léxica o lexicología, la semántica suboracional y la semántica oracional, así como la de estas con las perspectivas formales de la morfología y de la sintaxis suboracional y la sintaxis oracional. Para probar este aserto, en este artículo procedemos a 1) delimitar los niveles del contenido lingüístico o análisis semántico y las (sub) disciplinas semánticas y unidades lingüísticas que les corresponden; 2) clarificar hasta qué punto son dependientes los resultados de las investigaciones en semántica léxica o lexicología de los que arroja el análisis morfológico de la lengua; 3) caracterizar a la morfología y a la sintaxis como las disciplinas lingüísticas que estudian la proyección formal de las unidades léxicas, y 4) defender, en la sintaxis, una bifurcación entre una sintaxis suboracional y una sintaxis oracional, que tienen, como correlatos, una semántica suboracional y una semántica oracional.

Palabras clave: Léxico derivado. (Sub)disciplinas semánticas. Semántica morfológica. Semántica léxica o lexicología. Semántica suboracional. Semántica oracional. Morfología. Sintaxis suboracional. Sintaxis oracional.

* Esta contribución se inserta en el proyecto "Comunicación especializada y terminografía: usos terminológicos relacionados con los contenidos y perspectivas actuales de la semántica léxica" (FFI2014-54609-P), dirigido por el Prof. Dr. Miguel Casas Gómez y financiado por el Ministerio de Economía y Competitividad (Programa Estatal de Fomento de la Investigación Científica y Técnica de Excelencia. Subprograma Estatal de Generación del Conocimiento). 
Abstract: Investigation into the paradigmatic and syntagmatic dimensions of the derived lexicon contributes to revealing the interface of the (sub) disciplines of morphological semantics, lexical semantics or lexicology, sub-sentential semantics and sentential semantics, as well as that of these (sub) disciplines with the formal perspectives of morphology, sub-sentential syntax and sentential syntax. In order to prove this assertion, in this article we will 1) delimit the levels of linguistic content and semantic analysis and their corresponding semantic (sub) disciplines and linguistic units; 2) clarify the extent to which the results of the research in lexical se- mantics or lexicology depend on those of the morphological analysis of the language; 3 ) characterise morphology and syntax as the linguistic disciplines that study the formal projection of lexical units, and 4) defend a bifurcation in syntax between sub-sentential and sentential syntax, whose correlates are sub-sentential and sentential semantics.

Keywords: Derived lexicon. Semantic (sub)disciplines. Morphological semantics. Lexical semantics or lexicology. Sub-sentential semantics. Sentential semantics. Morphology. Sub-sentential syntax. Sentential syntax.

\section{REFLEXIONES INICIALES. A PROPÓSITO DE LAS (SUB)DISCIPLINAS SEMÁN- TICAS}

A unque reflejando una concepción no nueva en el ámbito de la lingüística, pero sí vigente en su época, es representativo el texto de Ullmann (33-38) en el que se le confiere un carácter transversal a dos disciplinas lingüísticas, la morfología y la semántica, pues en dicho texto el citado autor sostiene que ambas conforman las dos partes o subdivisiones tanto de la lexicología como de la sintaxis. En efecto, la lexicología es entendida por Ullmann como la rama de la lingüística que examina la palabra en todos sus aspectos y trata de la palabra y de los morfemas, las unidades mínimas significativas que intervienen en la formación de las palabras. Ahora bien, palabras y morfemas deben ser investigados en su forma y en su función, por lo que se plantea una división de la lexicología en morfología -la parte de la lexicología que tiene como objeto de estudio las formas de las palabras y de sus componentes- y semántica -la parte de la lexicología que tiene como objeto de estudio los significados de las palabras y de sus componentes-. Por su parte, la sintaxis estudia las frases y sus combinaciones, tanto desde el punto de vista de la forma como desde el punto de vista del significado. Por tanto, la sintaxis se divide también en morfología -la parte de la sintaxis en la que se incluye el estudio de la inflexión o flexión de las partes variables de la oración, el orden de palabras, el régimen, la concordancia, etc.- y semántica -la parte de la sintaxis que estudia los significados oracionales y las funciones semánticas de los elementos sintácticos-: ${ }^{1}$

1. Que las aserciones de Ullmann no son nuevas en el ámbito de la lingüística lo prueban ya, entre 
LEXICOLOGía: "se ocupa, por definición, de las palabras y de los morfemas formadores de palabras, es decir, de las unidades significativas. Se sigue que estos elementos deben ser investigados tanto en su forma como en su significado" (Ullmann 34)
MORFOLOGía: "estudio de las formas de las palabras y de sus componentes" (Ullmann 34)

SEMÁNTICA: "estudio de sus significados" (Ullmann 34)
SINTAXIS: "el estudio de las frases y sus componentes", que "tienen a la vez forma y significado” (UIImann 37)
MORFOLOGíA: "se ocupará de la inflexión, el orden de palabras, la concordancia (conveniencia), el régimen, y otros artificios útiles para la expresión de relaciones" (Ullmann 37-38)

SEMÁNTICA: "investigará los significados y las funciones de los elementos sintácticos" (Ullmann 38)

Y esto, porque

cuando se habla de semántica sin ningún calificativo, nos referimos usualmente al estudio del significado de las palabras propiamente dichas; pero es perfectamente normal, y de hecho muy común explorar la semántica de otros elementos, un sufijo, un prefijo, etc. (Ullmann 34).

En efecto, desde sus orígenes como ciencia lingüística en el primer cuarto del siglo XIX, la semántica, denominada inicialmente semasiología, ha estado casi siempre referida al estudio de los significados de las palabras, hasta tal punto que, incluso en la actualidad, para algunos investigadores es identificada con la semántica léxica, que, a su vez, puede ser diferenciada o no de la lexicología. ${ }^{2}$

otras, la concepción de Ries, quien distingue entre la lexicología, o ciencia de la palabra, y la sintaxis, o ciencia de la oración, y cada una de ellas tiene una morfología, centrada en el estudio meramente formal, y una semántica o ciencia de los significados.

2. Los autores que no establecen la identidad entre semántica léxica y lexicología se basan, por lo general, en que la lexicología implica una visión de los hechos semánticos del nivel léxico distinta a la planteada por la semántica léxica, pues la lexicología hace referencia exclusivamente 
No obstante, por lo general, hoy en día, es comúnmente admitido lo erróneo de tal concepción identificativa, pues supone obviar que otras unidades lingüísticas -en concreto, los morfemas, los sintagmas o grupos de palabras, las oraciones y los textos- tienen también significado y que este puede ser explorado e investigado, en el marco de esa disciplina global encargada del estudio de este que es la semántica, por alguna de las subdisciplinas (semánticas) que se delimiten en el seno de esta.

Prueba de que la semántica es entendida actualmente como una disciplina lingüística transversal es la proliferación de estudios semánticos a la que venimos asistiendo, ya desde el último tercio del siglo $\mathrm{XX}$, centrados en estos niveles de indagación del contenido lingüístico inferior y superiores al estrictamente léxico, esto es, en los niveles morfológico, suboracional o del grupo de palabras, oracional y textual, que ya son entendidos, al igual que el léxico, como niveles de análisis semántico de las lenguas. De ahí que, frente a la concepción tradicional de 'semántica es semántica léxica', resulte conveniente delimitar el nivel del estudio semántico, acompañando el término semántica de un adjetivo que especifique el nivel de contenido lingüístico en el que centramos nuestra indagación, y, así, que se hable de semántica morfológica, semántica léxica, semántica suboracional, semántica oracional y semántica textual.

Esta delimitación entre niveles del contenido lingüístico o de análisis semántico y estas otras tantas ciencias o disciplinas semánticas puede verse reflejada en la siguiente tabla:

\footnotetext{
al estudio de la forma del contenido, es decir, al estudio de los significados, y no al estudio de la sustancia del contenido, o de la designación y de las relaciones de designación. Por su parte, como es sabido, Coseriu prefiere, en lugar de lexicología, la denominación lexemática, que supone una investigación de los hechos semánticos del nivel léxico que, en el marco de la denominada lengua funcional (una lengua, en cuanto técnica del discurso, sincrónica y, al mismo tiempo, sintópica, sinstrática y sinfásica a la vez), atiende a las relaciones de significación de las denominadas palabras lexemáticas (ver $\$ 2$.) En este trabajo, dado que no nos centraremos específicamente en el tratamiento de los contenidos y las perspectivas nuevas de la semántica léxica, no se requiere la distinción, por lo que no optaremos por la delimitación semántica léxica I lexicología, sino que emplearemos indistintamente ambos términos.
} 


\begin{tabular}{|c|c|c|}
\hline $\begin{array}{l}\text { UNIDADES } \\
\text { LINGÜÍSTICAS } \\
\text { SIGNIFICATIVAS }\end{array}$ & $\begin{array}{l}\text { NIVELES DEL CONTENIDO } \\
\text { LINGÜÍSTICO O } \\
\text { NIVELES DE ANÁLISIS SEMÁNTICO }\end{array}$ & $\begin{array}{l}\text { CIENCIAS } \\
\text { O DISCIPLINAS } \\
\text { SEMÁNTICAS }\end{array}$ \\
\hline Textos & Nivel textual & Semántica textual \\
\hline Oraciones & Nivel oracional & Semántica oracional \\
\hline $\begin{array}{l}\text { Sintagmas o grupos de } \\
\text { palabras }\end{array}$ & $\begin{array}{l}\text { Nivel del grupo de } \\
\text { palabras o suboracional }\end{array}$ & $\begin{array}{l}\text { Semántica } \\
\text { suboracional }\end{array}$ \\
\hline Unidades léxicas ${ }^{3}$ & Nivel léxico & $\begin{array}{l}\text { Semántica léxica o } \\
\text { lexicología }\end{array}$ \\
\hline $\begin{array}{l}\text { Morfemas } \\
\text { Palabras morfemáticas }\end{array}$ & $\begin{array}{l}\text { Nivel } \\
\text { morfológico }\end{array}$ & $\begin{array}{l}\text { Semántica } \\
\text { morfológica }\end{array}$ \\
\hline
\end{tabular}

Y aun siendo conscientes de las múltiples conexiones y relaciones que se observan entre los compartimentos establecidos, de la existencia de fenómenos lingüísticos implicados en dos o más niveles de análisis y de las dificultades que plantea el establecimiento de estas "fronteras", todo ello debido a que, como es sabido, la lengua es una totalidad o entidad autónoma en la que todo se encuentra estrechamente interrelacionado, lo cierto es que, al menos metodológicamente, para la indagación semántica de la lengua, se procede, en la mayoría de las orientaciones lingüísticas, pero sobre todo en las que parten o se asientan en los postulados del estructuralismo lingüístico europeo, aceptando las delimitaciones marcadas en la tabla, que implican la asunción de una serie de presupuestos y principios teóricos, que, como ha sido mostrado, no siempre han estado vigentes, si bien son muy pocos los investigadores que hoy en día no son partícipes de ellos.

\section{MORFOLOGÍA, SEMÁNTICA MORFOLÓGICA Y SEMÁNTICA LÉXICA O LE- XICOLOGÍA}

En anteriores trabajos nuestros (ver Díaz Hormigo 2010a y 2010b) nos ocupamos de clarificar la delimitación entre las disciplinas lingüísticas morfología y semántica léxica o lexicología, previamente diferenciadas, en el marco global

3. A estas unidades léxicas, palabras con significado léxico, y a las palabras morfemáticas, o palabras con significado instrumental, haremos referencia en $\$ 2$. Ver también n. 7, en ese mismo epígrafe. 
de la linguiística, junto a la fonología, la sintaxis y semántica suboracionales, la sintaxis y semántica oracionales y la linguiistica del texto o textual, en correspondencia con los diferentes niveles distinguidos en el análisis de las lenguas (fonológico, morfológico, léxico, suboracional o del grupo de palabras, oracional y textual), integrados, a su vez, cada uno de ellos, por unidades (fonemas, morfemas, palabras, sintagmas o grupos de palabras, oraciones y textos).

Tales delimitaciones se muestran en la tabla siguiente:

\begin{tabular}{lll}
$\begin{array}{l}\text { CIENCIAS o } \\
\text { DISCIPLINAS LINGÜÍSTICAS }\end{array}$ & $\begin{array}{l}\text { NIIELES DE ANÁLISIS } \\
\text { LNGǗSTICO }\end{array}$ & $\begin{array}{l}\text { UNIDADES } \\
\text { LINGǗSTICAS }\end{array}$ \\
\hline $\begin{array}{l}\text { Lingüística del texto o } \\
\text { lingüística textual }\end{array}$ & Nivel textual & Textos \\
\hline $\begin{array}{l}\text { Sintaxis y semántica } \\
\text { oracionales }\end{array}$ & Nivel oracional & Oraciones \\
\hline $\begin{array}{l}\text { Sintaxis y semántica } \\
\text { suboracionales }\end{array}$ & $\begin{array}{l}\text { Nivel suboracional, } \\
\text { sintagmático, del grupo } \\
\text { de palabras o del sintagma }\end{array}$ & $\begin{array}{l}\text { Sintagmas o grupos } \\
\text { de palabras }\end{array}$ \\
\hline $\begin{array}{l}\text { Semántica léxica o } \\
\text { lexicología }\end{array}$ & Nivel léxico & Unidades léxicas \\
\hline Morfología & Nivel morfológico & Morfemas \\
\hline Fonología & Nivel fonológico & Palabras morfemáticas \\
\hline
\end{tabular}

En cualquier caso, en este marco, el análisis de las relaciones entre morfología y semántica léxica o lexicología implicó precisar, respecto a cada una de ellas, en qué sentido ha de ser definida; cuál debe ser considerado su objeto de estudio específico; qué contenidos abarca, y en qué líneas de indagación se ha centrado o especializado.

Pues bien, entre las cuestiones que abordamos, resulta de interés retomar aquí la referida a la definición de semántica morfológica, no como una disciplina autónoma en el marco de las disciplinas semánticas, caso este de la semántica léxica o lexicología, entre otras, sino como parte o subdisciplina de la morfología, pues las conclusiones obtenidas de esta indagación pueden contribuir ahora a clarificar hasta qué punto son dependientes las investigaciones en semántica léxica o lexicología de los resultados que arroje el análisis morfológico de la lengua.

En efecto, el advenimiento de la morfología estructural trajo consigo la 
superación de la concepción tradicional de la morfología como 'estudio solo de las formas' -manifestada, como hemos visto, en autores como Ullmann- ${ }^{4}$ y la asunción de que esta disciplina lingüística debe analizar la estructura interna de la palabra en tanto que constituida por una(s) forma(s) que es/son portadora(s) de una función, esto es, de un significado. ${ }^{5}$ Es, por tanto, objeto de la morfología atender a la segmentación o descomposición de la palabra en constituyentes formales menores portadores de un significado y analizar estas unidades mínimas significativas, o signos lingüísticos mínimos, que reciben, común e indistintamente, las denominaciones de morfemas o monemas (ver Trubetzkoy 270, Martinet 1960, 23 y Pena 372).

Ahora bien, la clasificación de los morfemas que propone la mayoría de los autores en sus diversos estudios (ver, entre otros, Hjelmslev, Alarcos, Martinet 1960 y 1968, Pottier 1964, 1967 y 1972, Roldán o Carratalá) implica una distinción, desde el punto de vista semántico, entre, por una parte, los denominados morfemas léxicos, lexemas, semantemas, pleremas o monemas léxicos, $\mathrm{y}$, por otra, los gramemas, monemas gramaticales, morfemas gramaticales o formantes.

Los primeros presentan, desde el punto de vista semántico, el denominado por Coseriu (1973, 81-83; 1976, 5-7; 1977, 247-49 y 1981, 3), en el marco de su caracterización de los significados de naturaleza lingüística, significado léxico, definido por el lingüista rumano como el correspondiente al qué de la aprehensión del mundo extralingüístico, propio y característico de las palabras que estructuran y representan la realidad extralingüística, esto es, de las denominadas por él palabras lexemáticas (sustantivos, adjetivos calificativos, verbos y adverbios léxicos), que son objeto de interés y estudio de la lexemática en sentido estricto coseriano pero solo en cuanto que son portadoras de una función léxica, o de un significado léxico, reflejo de esa estructuración y re-

4. No olvidemos que, desde el punto de vista etimológico, el vocablo morfología, del griego

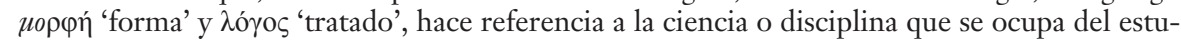
dio de la forma o formas que presentan los objetos que esa ciencia investiga, así como de las variantes que dichas formas pueden tener.

5. Recuérdense, en este sentido, entre otras afirmaciones contenidas en las definiciones de los lingüistas praguenses, las aserciones conducentes a la definición de lengua de la primera de las tesis del Cercle Linguistique de Prague (ver Trnka y otros 30-31) y la definición de lengua ofrecida a título individual, aunque haciéndola extensiva y reflejo del pensamiento del resto de los miembros del Cercle, por Mathesius (Trnka 249-50), de las que se infiere la condición esencial de finalidad, de función, que tienen todos los elementos de un sistema determinado, siendo precisamente la correspondencia de una función o significado a cada forma lo que posibilita el fenómeno de la comunicación. 
presentación primaria de la realidad por medio de las palabras. Atendiendo a la estructura morfológica de las palabras, este significado léxico es el aportado por el segmento formal de las mismas que se distingue como significante o morfo del llamado lexema o morfema léxico.

Por su parte, para el profesor de Tübingen es de carácter gramatical, instrumental o auxiliar -y compete su estudio a la morfología, o, más exactamente, de acuerdo con nuestra distinción, a la semántica morfológica- el significado de los signos lingüísticos mínimos que autores de diversas tendencias y metodologías, entre los que se encuentran los citados arriba, denominan gramemas, monemas gramaticales, morfemas gramaticales o formantes. Ahora bien, este significado no es definido por Coseriu, sino solo ejemplificado con las secuencias formales $e l$ en el hombre, que tiene el significado "actualizador", y $-s$, en mesa-s, a la que corresponde el significado "pluralizador", por lo que puede recibir también la denominación de significado morfológico. ${ }^{6}$

La distinción entre las disciplinas semánticas de semántica morfológica y semántica léxica o lexicología puede ser ejemplificada con la palabra venir, que interesa a la semántica léxica o lexicología únicamente en cuanto portadora de una función o significado léxico, representado por el segmento formal significante ven-, mientras que la función gramatical o significado morfológico "infinitivo", representado formalmente por la secuencia -ir, incumbe a la semántica morfológica o morfología (ver Coseriu 1966, 89).

Llegados a este punto, podríamos preguntarnos en qué sentido los denominados morfemas léxicos o lexemas competen a la morfología en tanto que disciplina que tiene como principal objeto el estudio de las formas y de los significados de las unidades menores -esto es, de los morfemas (todos)- que conforman las palabras. Y a este respecto observamos que la morfología, además de ocuparse de los procedimientos de delimitación de los morfemas, atendiendo para tal delimitación siempre al aporte de significado de cada unidad previamente distinguida, y del análisis de la problemática que suscita la segmentación de la palabra compleja en unidades mínimas significativas, ha desarrollado unas líneas de actuación centradas, casi en su totalidad, en la exploración de los morfemas gramaticales, relegando como objeto de estudio propio de la semántica léxica o lexicología prácticamente todo lo que

6. Este es también el significado de las denominadas por Coseriu palabras morfemáticas o instrumentales, que son las que funcionan en relación con otras palabras en la estructuración del hablar. Sirvan como ejemplos $y, o$, sobre, en, sí, etc. 
tiene que ver con la indagación semántica de los morfemas léxicos o lexemas. Así, respecto a estos, una vez delimitadas las unidades mínimas significativas que integran las palabras y sus correspondientes representantes fonológicos u ortográficos, la morfología se ha centrado en asignarles un significado a los morfemas léxicos, al igual que a los morfemas gramaticales, y a diferenciar las formas y las variantes formales que las realizaciones de estos morfemas léxicos pueden presentar, pues, al igual que los morfemas gramaticales, también los morfemas léxicos o lexemas, aunque tengan el mismo significado, pueden no siempre ser representados con la misma forma o aspecto fonológico u ortográfico, esto es, por un mismo y único morfo, sino que también las realizaciones de los morfemas léxicos pueden presentar variaciones formales o alomorfos. Y en este sentido, sobre todo, la morfología se ha ocupado también de determinar las variantes o modificaciones formales que se producen cuando los morfemas entran en contacto con otros morfemas en la palabra compleja y de especificar las causas o razones -de índole fonológica, morfofonológica, gramatical o léxica- de dicha alomorfía, ámbito este en el que la morfología confluye no solo con la semántica léxica o lexicología, sino también, al menos, con la fonología.

En cualquier caso, desde esta perspectiva, la semántica léxica o lexicología y la semántica morfológica, que se encargan de las unidades mínimas con significado léxico y morfológico, respectivamente, pueden ser entendidas como disciplinas semánticas subsidiarias formalmente, en cuanto a la estructura de sus constituyentes formales, de la morfología, pues es esta la que les proporciona el instrumentario teórico y la metodología procedimental para distinguir, inicialmente, las unidades que han de configurarse en sus correspondientes objetos de estudio. Ahora bien, ulteriormente, cada una de esas disciplinas semánticas ha desarrollado determinadas líneas de indagación respecto a las unidades que conforman sus objetos de estudio, centrándose la semántica morfológica, fundamentalmente, en los morfemas gramaticales y la semántica léxica o lexicología en todo lo referido al aspecto semántico de los denominados morfemas léxicos o lexemas en morfología y solo lexemas en semántica léxica o lexicología. Y es precisamente por el desarrollo de estas líneas de exploración de la semántica léxica o lexicología, con la adición, actualmente, de nuevos contenidos y perspectivas de enfoque a los tradicionalmente estudiados (ver Casas Gómez, así como el capítulo de introducción de este volumen) por los que esta disciplina semántica no puede ser considerada como una subdisciplina de la morfología, como sí lo es la semántica morfoló- 
gica, sino que goza, a diferencia de esta, de plena autonomía en el marco de las disciplinas semánticas. Tal vez correspondería a la semántica morfológica abrir nuevas líneas de investigación sobre el significado de los morfemas léxicos o lexemas, y abordar, entre otros temas,

la estructura del vocabulario de la lengua, su composición, variedad, origen, cambios históricos y adaptación a las condiciones sociales de la comunidad respectiva (ver Cerdà Massó 179, s.v. lexicología),

pero también la unidad semántica de las raíces léxicas, su mutabilidad e inmutabilidad semánticas, la motivación y las razones de la pérdida de la motivación de las mismas, etc., todo lo cual posibilitaría el establecimiento de las denominadas familias de palabras (ver Morera).

No obstante, puntos de contacto entre morfología y semántica léxica o lexicología se encuentran también al afrontar el estudio del modo de categorización de la realidad extralingüística aprehendida por las palabras que estructuran y representan esta realidad, esto es, las llamadas por Coseriu palabras lexemáticas, las cuales, además del significado léxico correspondiente al qué de la aprehensión, que les confiere un contenido semántico y un valor diferencial propio, presentan un determinado significado categorial -sustantivo, adjetivo, verbo o adverbio- que corresponde al cómo de esa aprehensión. Así el significado léxico es el significado común a todas las unidades de cada una de las series caliente - calor - calentar, frío (sust.) - frío (adj.) - enfriar, rico - riqueza - enriquecer, pobre - pobreza - empobrecer y, al mismo tiempo, diferencia cada una de estas series como un todo de otras series análogas, es decir, en virtud del significado léxico se distinguen rico y pobre, calor y frío (sust.), enriquecer y empobrecer, caliente y frío (adj.), calentar y enfriar, etc. Y el significado categorial es el diferente en cada unidad de cada una de las series enumeradas, pero el mismo en rico - pobre - caliente - frío (adj.), riqueza - pobreza - frío (sust.) - calor, enriquecer - empobrecer - enfriar - calentar, etc.

Por tanto, este significado categorial, que es el de las categorías lingüísticas -o categorías verbales, según la denominación coseriana-, implica una proyección formal de estas unidades léxicas que resultan de la estructuración de la realidad, por la que se configuran como pertenecientes a una determinada categoría lingüística, con sus específicas características no solo de constitución morfológica -y, en este sentido, indagadas por la morfología-, sino también de combinatoria sintáctica, y, por ello, objeto de estudio de la sintaxis. 


\section{MORFOLOGÍA Y SINTAXIS}

Son, por tanto, la morfología y la sintaxis las disciplinas lingüísticas que tienen como objeto de estudio la proyección formal de las unidades léxicas, y, en este sentido, el estudio de la(s) forma(s) que manifiestan tales unidades y de las relaciones formales que contraen tanto sus constituyentes entre sí como cuando estos constituyentes están combinados en niveles lingüísticos superiores. Ahora bien, a cada una de estas disciplinas compete un (sub)conjunto de relaciones formales lingüísticas. En efecto, la morfología, como disciplina encargada también, aunque no solo, del estudio de la(s) forma(s) lingüística(s), se ocupa de las relaciones formales que se dan dentro de la palabra entre las unidades menores dotadas de significado que las conforman -entre los morfemas-, y, por tanto, de la combinatoria de estas unidades mínimas significativas en las palabras, así como de la clasificación de las palabras en categorías lingüísticas, aspecto este en el que, no obstante, figuran también unidos o combinados los criterios morfológico, lexicológico y sintáctico. Por su parte, la sintaxis aborda el estudio de las relaciones formales que contraen las palabras en las unidades lingüísticas superiores que son sintagmas o grupos de palabras $\mathrm{u}$ oraciones, relaciones estas que configuran la combinatoria de esas unidades.

\section{SINTAXIS Y SEMÁNTICA SUBORACIONALES Y ORACIONALES}

Ahora bien, desde hace años (aunque ver, sobre todo, Díaz Hormigo 1999a) defendemos que, al menos metodológicamente, es necesario delimitar, en la disciplina o ciencia lingüística denominada sintaxis, entre una sintaxis suboracional y una sintaxis oracional, que se ocupen, respectivamente, de los fenómenos y aspectos lingüísticos que atañen a los sintagmas o grupos de palabras y a las oraciones, o sea, a las unidades lingüísticas de los niveles sintácticos suboracional y oracional. A estas disciplinas de la sintaxis suboracional y la sintaxis oracional corresponden, como correlatos, las disciplinas semántica suboracional y semántica oracional, encargadas, por tanto, del análisis e indagación de los niveles semántico suboracional y oracional de las lenguas. En efecto, en este nivel sintáctico-semántico suboracional se atenderán todos aquellos temas para cuya investigación no es necesario partir del análisis de una oración, aunque tampoco basta con considerar a los sustantivos, adjetivos calificativos o adverbios léxicos aisladamente, sino que hay que situar el estudio en el nivel intermedio entre el de palabra y el de la oración. Nos indujo 
a postular esta bifurcación del nivel sintáctico en suboracional y oracional la observación de que, dependiendo de la concepción que un autor tuviera de un determinado aspecto lingüístico, hacía que lo considerara como del nivel de la palabra o como del nivel de la oración. E incluso, a veces, se procede arbitrariamente y se incluyen indistintamente, en los apartados dedicados a la "Morfología" o a la "Sintaxis" de gramáticas, monografías y tratados de lingüística, el análisis de aspectos lingüísticos, como, por ejemplo, los fenómenos de la transitividad e intransitividad y el de los complementos de sustantivos, adjetivos y adverbios núcleos de sintagmas. Estos temas, desde nuestra perspectiva, deben ser indagados situándolos en el nivel sintáctico-semántico suboracional, en el que, además de los mencionados y otros como el de la posición del adjetivo calificativo respecto al sustantivo núcleo del sintagma nominal, del que resulta una clasificación semántica de los adjetivos calificativos según la posición que ocupan; el de la incidencia del adverbio sobre el adjetivo, y el de la gradación comparativa y superlativa del adjetivo calificativo, se examinan también, fundamentalmente, las estructuras de las construcciones con sustantivos, adjetivos calificativos y adverbios en posición nuclear, con independencia de cuál sea la función sintáctico-semántica que desempeñen en la oración.

Pues bien, en este marco de las disciplinas lingüísticas de la sintaxis y semántica suboracionales, se sitúan nuestras investigaciones referidas, sobre todo, a las construcciones con sustantivo en posición nuclear (ver Díaz Hormigo 1994a, 1994b y 1998a). Respecto a estas, las que nos interesa destacar ahora $^{7}$ son nuestras incursiones y análisis de las correspondencias entre complementos verbales y complementos nominales y de las correspondencias entre expresiones oracionales y construcciones suboracionales que tienen como núcleos sustantivos derivados deverbales, deadjetivales, desustantivales o deadverbiales, así como sobre la sintaxis interna de las formaciones derivadas (ver Díaz Hormigo 1999b, 2000b y 2005), pues tales investigaciones vienen a dar cuenta de que los procesos morfológicos derivacionales se proyectan, formal y semánticamente, tanto en la sintaxis suboracional y oracional como también en la semántica suboracional y oracional.

7. Pues también hemos indagado la perspectiva funcional de las construcciones suboraciones en el sentido propuesto por Firbas para las oraciones - por tanto, estudiándolas dentro del texto- y, de ahí también, atendiendo a los conceptos praguenses tema y rema, la función temática que, fundamentalmente, desempeñan tales construcciones suboracionales en el dinamismo lineal del discurso, los fenómenos de la transitividad e intransitividad suboracionales y la ambigüedad de las construcciones del tipo amor dei y timor hostium en diferentes lenguas (ver Díaz Hormigo 1993, 1995-96, 1998b, 2000a y 2004). 
En efecto, el análisis de la estructura interna de la formación derivada se ocupa de mostrar si el resultado de un proceso derivativo -la formación derivada-incorpora o no alguna de las valencias o argumentos de la categoría que le sirve de base. Para ello se intentan establecer entre los significados de las unidades lingüísticas (lexemas y morfemas) que conforman la estructura interna de las formaciones derivadas relaciones semejantes a las que se establecen en la oración entre las unidades lingüísticas que desempeñan las diferentes funciones sintácticas.

Por su parte, el estudio de la sintaxis externa de las formaciones derivadas tiene como finalidad determinar si la formación derivada conserva, total o parcialmente, la estructura argumental -también llamada red temática, esquema de valencias semánticas, estructura valencial- de la categoría primitiva que le sirve de base de derivación o si, por el contrario, presenta una estructura argumental diferente. La estructura argumental está constituida por el conjunto de los complementos seleccionados semánticamente por el núcleo de la construcción, que son denominados argumentos o valencias sintácticas de la categoría que los selecciona y se corresponden, cada uno de ellos, con una función semántica, una valencia semántica, un rol casual o un papel temático, de acuerdo con las diferentes denominaciones de diferentes perspectivas metodológicas de la lingüística. Y la correspondencia, en el caso de que se dé, total o parcialmente, entre la estructura argumental de la formación derivada y la estructura argumental de la categoría primitiva se establece y, en consecuencia, ha de interpretarse y puede ser descrita desde las perspectivas tanto sintáctica como semántica.

Desde este punto de vista, nuestros análisis sobre la sintaxis externa de los sustantivos derivados de verbos, nos han mostrado que cuando el sustantivo deverbal presenta un significado de "acción", "efecto" o "actitud" sí se establece una correspondencia sintáctico-semántica total entre la estructura argumental del verbo que es base de la derivación y la del sustantivo, pues ambos presentan el mismo número de argumentos o valencias sintácticas y, además, estas tienen idéntico carácter sintáctico-semántico, si bien en la estructura sintagmática nominal estas valencias están siempre precedidas de alguna preposición. Sirvan como ejemplos la estructura argumental del verbo conspirar, que tiene dos argumentos, el agente y el objeto (Agente Alguien conspira Objeto contra alguien / algo) y la estructura argumental del sustantivo conspiración: conspiración Agentede alguien Objeto contra alguien / algo.

Ahora bien, no todas las estructuras argumentales con un sustantivo deverbal nuclear que significa "acción", "efecto" o "actitud" están relacionadas con 
una única estructura argumental oracional, ya que determinadas estructuras sintagmáticas nominales se corresponden solo sintácticamente con la estructura argumental oracional pasiva y solo semánticamente con la estructura oracional activa. Así, la estructura argumental suboracional del sustantivo deverbal decoración, que es decoración Objeto de algo Agentepor parte de alguien se corresponde solo sintácticamente con la estructura argumental pasiva Objeto Algo es decorado Agentepor parte de alguien y solo semánticamente (función de la forma) con la estructura argumental activa Agente Alguien decora Objetolgo, ya que el sustantivo deverbal y el verbo núcleo de la estructural argumental activa indican "acción", mientras que el verbo núcleo de la estructura argumental pasiva indica "proceso".

Asimismo, constatamos que las estructuras sintagmáticas que presentan como núcleo un sustantivo deverbal de los denominados tradicionalmente nombres de agente no manifiestan una identidad o correspondencia total sino parcial con las respectivas estructuras oracionales, ya que el sustantivo nuclear de "agente" expresa el contenido de "acción" y de "agente", por lo que la estructura sintagmática nominal tiene un argumento o una valencia menos que la estructura oracional, más específicamente, la estructura suboracional no presenta ninguna valencia con la función semántica o papel temático "agente", puesto que el sustantivo deverbal núcleo de la estructura sintagmática ya incluye este contenido. Citemos como ejemplo la estructura sintáctico-semántica del sustantivo deverbal decorador, que es decorador de Objeto algo, estructura que mantiene solo una de las dos valencias o argumentos de la estructura oracional. De ahí que, refiriéndose a la sintaxis interna de los sustantivos deverbales, determinados autores, como Laca (1986 y 1993), diferencien las nominalizaciones no orientadas o predicativas de las nominalizaciones orientadas, pues estas "incorporan un argumento específico del lexema verbal de base", concretamente "el argumento correspondiente al sujeto del verbo de base en una construcción activa" (Laca 1993, 187 y 191), mientras que las nominalizaciones no orientadas o predicativas presentan una estructura sintáctica que no incorpora o no absorbe ningún argumento de la base de la formación, tal como se observa si comparamos la expresión oracional Fleming descubrió la penicilina con sus correspondientes nominalizaciones no orientada o predicativa El descubrimiento de la penicilina por Fleming y orientada El descubridor de la penicilina y no ${ }^{*}$ El descubridor de la penicilina por parte de alguien.

8. La función sintáctica sujeto engloba los diferentes roles casuales (agente, experimentador, instrumento, causa, etc.) que puede desempeñar este argumento del verbo base. 
En cualquier caso, lo que sí está claro es que tanto la indagación de la denominada sintaxis interna como la de la sintaxis externa de las formaciones derivadas sobrepasa los límites del nivel de los morfemas y del de las palabras, puesto que hay que tener en cuenta las respectivas combinatorias tanto sintácticas como semánticas de las categorías primitivas y de las categorías derivadas, lo que implica situar esta indagación en los niveles superiores al morfológico y al léxico, o sea, en los niveles sintáctico y semántico suboracional y oracional.

\section{LA INTERRELACIÓN DE LOS NIVELES DE INDAGACIÓN SEMÁNTICA}

A este respecto, nuestras investigaciones se sitúan en el marco de la teoría de los esquemas sintáctico-semánticos, desarrollada, fundamentalmente, por Báez San José (1987, 1993, 1996 y 2002, y Báez San José y Penadés Martínez) y que se basa en la distinción entre un nivel de análisis abstracto o estático de las oraciones, cuyo objeto es la constitución y estudio de los denominados esquemas sintáctico-semánticos de estas unidades lingüísticas, y un nivel de análisis concreto o dinámico, en el que se procede a la indagación de estos esquemas sintáctico-semánticos insertos en el dinamismo lineal del discurso. Desde nuestro punto de vista (ver Díaz Hormigo 1994a, 1994b, 1998a y 1999a), esta división del nivel oracional puede ser trasladada al nivel del sintagma o grupo de palabras y, en consecuencia, diferenciar entre un subnivel de análisis e indagación de los mismos abstracto o estático, cuyo objeto es la constitución y estudio de los esquemas sintáctico-semánticos de los sintagmas suboracionales, y un subnivel concreto o dinámico, en el que se lleva a cabo el examen de los mismos en el discurso, pues cualquier sintagma o grupo de palabras con sustantivo, adjetivo calificativo o adverbio en posición nuclear es actualización de un esquema sintáctico-semántico suboracional subyacente.

En cualquier caso, dejando momentáneamente a un lado el marco de indagación señalado, desde una perspectiva general, no debemos olvidar que las palabras derivadas, que responden a un determinado mecanismo de formación de palabras que, en tanto que proceso de creación léxica, es estudiado formal y semánticamente en morfología y, como resultado o producto, en semántica léxica o lexicología presentan, respecto a las palabras primitivas que les sirven de base de derivación, un significado léxico común, en el sentido epistemológico coseriano, correspondiente al qué de la aprehensión, si bien pueden, o no, diferenciarse de estas en el significado categorial si, por su pro- 
yección formal morfológica, pertenecen a una categoría lingüística distinta. Por ello, el análisis de la proyección formal sintáctica y de la proyección semántica del léxico derivado, que nos lleva a la indagación de su combinatoria sintáctico-semántica suboracional y a la correspondencia de esta con estructuras argumentales del nivel oracional, muestra la confluencia de los niveles de indagación semántica que, al menos metodológicamente, suelen distinguirse, en concreto, de los niveles semántico morfológico, léxico, semántico suboracional y semántico oracional.

\section{NUEVAS PERSPECTIVAS DE ANÁLISIS DEL LÉXICO DERIVADO}

El panorama esbozado contribuye a revelar, al menos en parte, la interrelación de las disciplinas lingüísticas, formales y semánticas, encargadas del estudio de los diferentes niveles de análisis de la lengua. Pero también sirve para mostrar nuevas posibilidades y perspectivas de indagación de las unidades lingüísticas que comparten un significado léxico común, investigaciones centradas, sobre todo, en las manifestaciones de la proyección morfológica y sintáctico-semántica suboracional y oracional de este significado léxico.

En este sentido, puede resultar de gran interés proceder a la determinación de las estructuras argumentales de las unidades léxicas que comparten un significado léxico común y, ulteriormente, al estudio de la correspondencia entre tales estructuras argumentales, temas estos en los que se observan, de manera candente, deficiencias, insuficiencias y lagunas por parte de las diferentes corrientes lingüísticas que los han abordado: gramática generativa transformacional en sus diferentes modelos o versiones, gramática de dependencias y desarrollos posteriores de la teoría de la valencia, gramática de casos, semántica generativa, e incluso determinados acercamientos al estudio de la 'oración' por parte de los autores de la primera Escuela de Praga, la Nueva Escuela de Praga y otras corrientes insertas en el estructuralismo lingüístico europeo y americano, de las cuales ya dieron cuenta, entre muchos otros, Devís Márquez, Espinosa García y Díaz Hormigo (1998a).

En cualquier caso, desde nuestra perspectiva, tales acercamientos a las proyecciones morfológica, sintáctica y semántica del léxico debe pasar por a) la delimitación de las series de unidades léxicas que presentan un significado léxico común, en el sentido definido por Coseriu (ver $\$ 2$.); b) la determinación de las estructuras sintáctico-semánticas oracionales en las que figura como núcleo predicativo, atributo o complemento predicativo el verbo, el 
adjetivo calificativo, el adverbio y/o incluso el sustantivo que conforman la serie de unidades léxicas previamente delimitadas; c) el establecimiento de las estructuras argumentales sintagmáticas con sustantivos, adjetivos calificativos y adverbios en posición nuclear; d) la confrontación de las estructuras argumentales oracionales y suboracionales de las unidades léxicas que constituyen la serie para averiguar si es posible hallar alguna correspondencia; e) en el caso de que esta correspondencia se dé, con cuál de las estructuras argumentales de una misma unidad léxica se establece tal correspondencia; f) si, en el caso en que se dé, la correspondencia entre las estructuras es total o parcial, y g) si, en el caso en que se dé, esta correspondencia, total o parcial, ha de interpretarse y puede describirse solo desde un punto de vista sintáctico, solo desde un punto de vista semántico o desde ambas perspectivas.

A modo de ejemplo de nuestra propuesta, piénsese en las unidades léxicas constatar y constatación, que, según la última edición del Diccionario de la lengua española de la Real Academia, presentan las acepciones de, respectivamente, constatar "tr. Comprobar un hecho, establecer su veracidad, dar constancia de él” y constatación "1. f. Acción y efecto de constatar". Pues bien, desde nuestro punto de vista, estas acepciones del verbo y del sustantivo nos permiten afirmar que estas palabras con diferente significado categorial presentan un significado léxico común en el sentido coseriano y, por tanto, que forman parte de la misma serie. En este sentido, con el significado léxico reflejado en la acepción del verbo registrada en el diccionario académico, le corresponden a esta unidad léxica, al menos, las estructuras argumentales sintáctico-semánticas
1a. Agente Alguien constata Tema algo
1b. TemaAlgo es constatado Agente por parte de alguien
1c. TemaAlgo está constatado Agente por parte de alguien

y al sustantivo

\section{2a. constatación Temade algo Agentepor parte de alguien}

Como ya mencionamos en $\$ 4$., al establecer las estructuras argumentales sintáctico-semánticas de decorar y decoración, una misma estructura argumental suboracional puede tener correspondencia con dos o más estructuras argumentales oracionales distintas. En efecto, la estructura suboracional de 
constatación citada en 2a, constatación Temade algo Agentepor parte de alguien, muestra, al menos, correspondencia con las tres estructuras argumentales distintas del verbo constatar establecidas, que son la activa, la pasiva y la resultativa (citadas, respectivamente, en 1a, 1b y 1c). Ahora bien, las valencias de las estructuras argumentales suboracional, oracional activa, oracional pasiva y oracional resultativa coinciden en los papeles temáticos o roles casuales, los de agente y tema, pero son diferentes las funciones sintácticas de las valencias en la estructura argumental activa y en las pasiva y resultativa. Por ello, defendemos (ver Díaz Hormigo 2000a) que la correspondencia entre, al menos las valencias del sustantivo que funciona como núcleo de la estructura argumental suboracional y las del verbo núcleo predicativo de la estructura argumental activa y de las pasiva y resultativa se establece, y puede ser descrita con mayor propiedad, desde el punto de vista semántico y no desde el punto de vista sintáctico. Y, en este sentido, habría de afirmarse que el sustantivo deverbal presenta el argumento del verbo que tiene determinada función semántica o papel temático, sin mencionar la función sintáctica que este argumento desempeña en la estructura argumental oracional, ya que esta función sintáctica difiere, como hemos señalado, según si atendemos a una estructura argumental o a las otras.

Este aserto, aunque se cumple, no es tan particularmente evidente para los sustantivos que son núcleos de estructuras argumentales que se corresponden con solo una estructura argumental oracional, como es el caso de, entre muchos otros, los sustantivos de "actitud" amor y temor, núcleos de las estructuras sintáctico-semánticas amor / temor afectado portador de la actitudde alguien objeto de la actitudpor/bacia algo/alguien, que se corresponden con las estructuras argumentales oracionales afectado portador de la actitud alguien amal teme objeto de la actitud algo/a alguien.

Sin embargo, nuestra propuesta de que lo correcto es afirmar que el sustantivo deverbal presenta el argumento del verbo que tiene determinada función semántica o papel temático, sin mencionar la función sintáctica que este argumento desempeña en la estructura argumental oracional, es especialmente fructífera en el análisis de series léxicas como 1) percibir 'recibir algo y encargarse de ello' y percepción 'acción y efecto de percibir'; 2) percibir 'captar por uno de los sentidos las imágenes, impresiones o sensaciones externas' y percepción 'acción y efecto de percibir', y 3) percibir 'comprender o conocer algo' y percepción 'acción y efecto de percibir', pues el significado léxico, que aun siendo común a las unidades que constituyen cada una de las series, di- 
ferencia cada una de las series como un todo de las otras series se manifiesta también en diferentes estructuras semánticas en cada pareja de las unidades léxicas, mientras que las estructuras sintácticas son las mismas para cada verbo y sustantivo de las series.

En efecto, la forma verbal percibir, con significados léxicos diferentes en cada serie, es núcleo predicativo de las estructuras sintácticas activa y pasiva

Alguien percibe algo $\mathrm{y}$

Algo es percibido por parte de alguien.

Y percepción, también con significados léxicos diferentes en cada serie, es núcleo de la estructura sintáctica

percepción de algo por parte de alguien.

Sin embargo, si atendemos a las estructuras argumentales semánticas, estas difieren, pues son,

1) para las unidades léxicas de la serie percibir 'recibir algo y encargarse de ello' y percepción 'acción y efecto de percibir'

Agente Alguien percibe Objeto afectado algo

Objeto afectado Algo es percibido Agentepor parte de alguien percepción Objeto afectado de algo Agentepor parte de alguien;

2) para las unidades léxicas de la serie percibir 'captar por uno de los sentidos las imágenes, impresiones o sensaciones externas' y percepción 'acción y efecto de percibir'

Agente Alguien percibe Temalgo

TemaAlgo es percibido Agentepor parte de alguien

percepción Temade algo Agentepor parte de alguien,

y 3$)$ para las unidades léxicas de la serie percibir 'comprender o conocer algo' y percepción 'acción y efecto de percibir'

Agente Alguien percibe Objeto cuantificador algo 


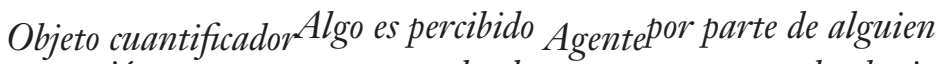 percepción Objeto cuantificador de algo Agentepor parte de alguien,}

lo que muestra también que los diferentes significados de las unidades léxicas formalmente idénticas se diferencian entre sí por ser estas núcleos de diferentes estructuras sintáctico-semánticas oracionales y suboracionales.

En cualquier caso, la investigación propuesta sobre la proyección formal y semántica de las unidades léxicas que conforman series por presentar un significado léxico común se verá indudablemente enriquecida si, por una parte, se analizan las palabras derivadas que intervienen en las respectivas series no solo como productos de un mero mecanismo morfológico de formación de palabras, sino también desde el punto de vista del contenido y, en este sentido, como resultados de uno u otro de los procedimientos semánticos de formación de palabras señalados por Coseriu (1978 y 1981) en el marco de su teoría de las estructuras paradigmáticas secundarias distinguibles en el léxico de la lengua, esto es, como resultados de la modificación, el desarrollo o la composición. Y, por otra parte, además, se sitúa la indagación en el marco de la teoría de los esquemas sintáctico-semánticos de Báez San José (ver \$5.). Así, aunando la teoría coseriana de la formación de palabras desde el punto de vista del contenido y los presupuestos de la teoría de los esquemas sintácticosemánticos, hemos procedido ya (ver Díaz Hormigo 1996 y 1997) al análisis de estructuras paradigmáticas secundarias por desarrollo predicativo y demostrado que el establecimiento de los esquemas sintáctico-semánticos de la unidad léxica base del desarrollo y de la unidad léxica desarrollada posibilita, entre otros temas, la indagación de si se transfieren las características sintáctico-semánticas de una unidad léxica a otra, la existencia de casillas vacías en el léxico y el problema de las homofonías. No obstante, esta indagación, además de a las demás unidades léxicas que se ajustan a las relaciones de desarrollo predicativo, habría de ampliarse y hacerla extensiva a las otras series de unidades léxicas de la lengua que respondan o bien a alguno de los otros subtipos de relaciones del mecanismo del desarrollo -el desarrollo atributivo y el desarrollo de objetos preposicionales- o bien a alguno de los subtipos de los otros dos procedimientos formativos léxicos fundamentales, la modificación y la composición, esta última solo en lo que se refiere al subtipo de la composición prolexemática. 


\section{A MODO DE RECAPITULACIÓN}

Pues bien, como recapitulación, podemos indicar que en esta contribución hemos procedido a delimitar las disciplinas lingüísticas encargadas del estudio del contenido lingüístico, con sus correspondientes niveles de indagación semántica y las unidades lingüísticas significativas insertas en cada uno de estos niveles, haciéndonos eco para ello, aunque parcialmente, tanto de la demarcación propuesta por Ullmann como de las distinciones de Coseriu para marcar los límites epistemológicos entre lo lexicológico (entiéndase lexicología en el sentido propio coseriano) y lo gramatical o morfológico basándose en los diferentes tipos de significado lingüístico. $\mathrm{Y}$, a estas, centrándonos en el ámbito de la lingüística hispánica, podemos añadir las consideraciones del semantista español Trujillo, quien defiende, igualmente, que, aunque la única ciencia del contenido es la semántica, esta puede dividirse en semántica gramatical o gramática (léase semántica morfológica o morfología), ${ }^{9}$ que tiene como objeto las formas de contenido que resulten analizables en los componentes del significante, esto es, las formas de contenido "arquitecturales" de la lengua, y la semántica léxica o lexicología, a la que interesan las formas de contenido que no son analizables en el plano del significante, o no "arquitecturales". Por ello, al ocuparse este autor de las diversas modalidades de estudio existentes desde el punto de vista del contenido, se refiere a las disciplinas de la gramática y la lexicología que tienen en común, además de ocuparse del estudio de las formas de contenido, el que, aunque no pueden prescindir del conocimiento de los significantes, su objeto no son estos como tales significantes sino solo como índices de formas de contenido.

En cualquier caso, la aceptación de la existencia de diversas (sub)disciplinas semánticas, en el marco de una ciencia semántica general encargada del estudio del significado lingüístico, no implica la asunción de que los componentes o niveles de análisis semánticos correspondientes a estas (sub)disciplinas estén claramente definidos y que las fronteras no sean borrosas sino que estén perfectamente trazadas. Por el contrario, lo que sí hemos intentado mostrar con nuestra exposición es que, a pesar de las imbricaciones de los

9. En este artículo, Trujillo emplea el término gramática para hacer referencia a la morfología y para comprobar esta aserción basta con atender a los ejemplos de carácter gramatical que aparecen en este artículo, que son todos morfológicos. En efecto, el autor citado se refiere tanto a que los significantes $-b a$ e -ía representan el valor o la forma de contenido "pretérito imperfecto" como a las relaciones de forma de contenido gramatical entre las parejas gato-gata y perro-perra. 
contenidos que cada (sub)disciplina semántica abarca y la existencia de fenómenos lingüísticos a caballo entre dos o más componentes o niveles, y, por ende, entre dos o más (sub)disciplinas, cada una de estas se ha centrado o especializado en unas líneas de indagación determinadas, que hace que, al menos metodológicamente, las confluencias o puntos de contacto entre ellas queden diluidos en la investigación empírica. Otra cuestión es que optemos por analizar las unidades lingüísticas de un nivel de análisis, o un determinado fenómeno lingüístico concreto, observando su proyección hacia otros niveles de estudio y, por tanto, aunando el instrumental teórico, conceptual y metodológico de las (sub)disciplinas encargadas de la indagación de estos niveles. Es precisamente en esta idea en la que se basa la propuesta de estudio que aquí hemos formulado para un sector del léxico, el derivado, respecto al cual, atender a sus dimensiones paradigmática y sintagmática implica traer a colación las (sub)disciplinas semánticas de la semántica morfológica, la semántica léxica o lexicología, la semántica suboracional y la semántica oracional, así como las perspectivas formales de la disciplina morfología y de la sintaxis suboracional y la sintaxis oracional.

\section{OBRAS CITADAS}

Alarcos Llorach, Emilio. Gramática estructural (según la escuela de Copenhague y con especial atención a la lengua española). 1951. 2. ${ }^{\text {a }}$ ed. Madrid: Gredos, 1981.

Báez San José, Valerio. “Oración y esquema oracional”. Lingüística Española Actual 9 (1987): 65-82.

Báez San José, Valerio. "Funciones sintagmáticas y los niveles del acto de hablar, la expresión y el esquema oracional". Actes du XXe Congrès International de Linguistique et Philologie Romanes. Université de Zurich (6-11 avril 1992). Tome I: Séance d'ouverture. Section I - La phrase. Ed. Gerold Hilty. Tübingen/Basel: Francke, 1993. 71-84.

Báez San José, Valerio. "Desde una lingüística del hablar a una lingüística de las lenguas". I Fornadas de Linguiistica. Con motivo de la implantación de la especialidad de Linguística en la Universidad de Cádiz (24 y 25 de octubre de 1995). Ed. Miguel Casas Gómez. Cádiz: Universidad de Cádiz, 1996. 135-85.

Báez San José, Valerio. Desde el hablar a la lengua. Prolegómenos a una teoría de la sintaxis y la semántica textual y oracional. Málaga: Ágora, 2002. 
Báez San José, Valerio e Inmaculada Penadés Martínez. "Diccionario de construcciones oracionales y el proyecto Esquemas sintáctico-semánticos del español'. Lingüística Española Actual 12 (1990): 103-36.

Carratalá, Ernesto. Morfosintaxis del castellano actual. Barcelona: Labor, 1980.

Casas Gómez, Miguel. "Contenidos actuales de la semántica léxica: la terminología”. Lexikalische Semantik und Korpuslinguistik. Eds. Wolf Dietrich y otros. Tübingen: Gunter Narr, 2006. 13-40.

Cerdà Massó, Ramón, coord. Diccionario de lingiiústica. Madrid: Anaya, 1986. Coseriu, Eugenio. "Structure lexicale et enseignement du vocabulaire". Actes du premier colloque international de linguistique appliquée (Nancy, 1964). Nancy: Université de Nancy. Faculté des Lettres et des Sciences Humaines, 1966. 175-17.

Coseriu, Eugenio. "Semantik und Grammatik". Neue Grammatiktheorien und ibre Anwendung auf das heutige Deutsch [= Jahrbuch 1971 des Instituts für deutsche Sprache]. Dusseldorf: Pädagogischer Verlag Schwann, 1973. 77-89.

Coseriu, Eugenio. "L'étude fonctionnelle du vocabulaire". Cahiers de Lexicologie 29 (1976): 5-23.

Coseriu, Eugenio. "La «situación» en la Lingüística". El hombre y su lenguaje. Madrid: Gredos, 1977. 240-56.

Coseriu, Eugenio. "La formación de palabras desde el punto de vista del contenido (a propósito del tipo "coupe-papier")". Gramática, semántica, universales. Estudios de lingüística funcional. Madrid: Gredos, 1978. 239-64.

Coseriu, Eugenio. "Les procédés sémantiques dans la formation des mots". Cabiers Ferdinand de Saussure 35 (1981): 3-16.

Devís Márquez, Pedro Pablo. Esquemas sintáctico-semánticos: el problema de las diátesis en español. Cádiz: Universidad de Cádiz, 1993.

Díaz Hormigo, María Tadea. "Sobre la función temática de los sustantivos deverbales y deadjetivales dentro de la tricotomía texto, expresión textual, esquema oracional". Actes du XX Congrès International de Linguistique et Philologie Romanes. (Université de Zurich, 6-11 avril 1992). Tome I: Séance d'ouverture. Section I - La phrase. Ed. Gerold Hilty. Tübingen/ Basel: Francke, 1993. 191-204.

Díaz Hormigo, María Tadea. "El concepto de esquema sintáctico-semántico de construcción con sustantivo nuclear". Panorama de la Investigació Lingüística a l'Estat Espanyol. Actes del I Congrés de Lingüistica General. Volum II. Co- 
municacions: Gramàtica i Lingüística formal. Eds. Enrique Serra Alegre y otros. Vol 2. València: Universitat de València, 1994a. 40-46.

Díaz Hormigo, María Tadea. Esquemas sintáctico-semánticos de las construcciones con sustantivo en posición nuclear. Tesis de doctorado en microficha. Cádiz: Universidad de Cádiz, 1994b.

Díaz Hormigo, María Tadea. "Sobre la transitividad e intransitividad suboracionales”. Pragmalingüística 3-4 (1995-96): 289-10.

Díaz Hormigo, María Tadea. "Las estructuras paradigmáticas secundarias por desarrollo predicativo y la teoría de los esquemas sintáctico-semánticos". Contextos XIV/27-28 (1996): 65-105.

Díaz Hormigo, María Tadea. "Esquemas sintáctico-semánticos de unidades constituyentes de estructuras paradigmáticas secundarias. A propósito del desarrollo predicativo". Estudios de Lingüistica General (III). Trabajos presentados en el II Congreso Nacional de Lingüistica General (Granada, 25 al 27 de marzo de 1996). Eds. José Andrés de Molina Redondo y Juan de Dios Luque Durán. Vol. 3. Granada: Granada Lingvistica y Método Ediciones, 1997. 93-105.

Díaz Hormigo, María Tadea. Sintaxis y semántica de la construcción con sustantivo en posición nuclear. LynX. Annexa 11. University of Minnesota (USA)/ Universitat de València (España): Department of Spanish and Portuguese/Departament de Teoria dels Llenguatges, 1998a.

Díaz Hormigo, María Tadea. "Para una revisión de los conceptos praguenses tema y rema". Retórica y Texto. Coords. Antonio Ruiz Castellanos, Antonia Víñez Sánchez y Juan Sáez Durán. Cádiz: Universidad de Cádiz, 1998b. 231-34.

Díaz Hormigo, María Tadea. "Puntos de contacto entre sintaxis oracional y sintaxis suboracional: la correspondencia entre complementos verbales y complementos nominales". Lingiuistica para el siglo XXI. Eds. Jesús Fernández González, Carmen Fernández Juncal, Mercedes Marcos Sánchez, Emilio Prieto de los Mozos y Luis Santos Río. Vol. 1. Salamanca: Ediciones Universidad de Salamanca, 1999a. 461-68.

Díaz Hormigo, María Tadea. "El estatus lingüístico del nivel suboracional". Estudios de Linguiística Descriptiva y Comparada. Trabajos presentados en el III Simposio Andaluz de Lingüistica General (Sevilla: 15-17 marzo 1999). Eds. Ángel Yanguas y Francisco José Salguero. Sevilla: Editorial Kronos, 1999b. 89-95.

Díaz Hormigo, María Tadea. "A propósito de las construcciones nominales 
ambiguas del tipo amor dei y timor hostium en diferentes lenguas”. Linguiistica 12 (2000a): 185-10.

Díaz Hormigo, María Tadea. "La correspondencia sintáctico-semántica entre expresión oracional y construcción con sustantivo en posición nuclear". Actes du XXII Congrès International de Linguistique et de Philologie Romanes. Université Libre de Bruxelles, 23-29 juillet 1998, tome VI: De la grammaire des formes à la grammaire du sens. Eds. Annick Englebert, Michel Pierrard, Laurence Rosier y Dan van Raemdonck. Vol. 6. Tübingen: Max Niemeyer, 2000b. 139-45.

Díaz Hormigo, María Tadea. "Hacia la formulación de una teoría sobre la perspectiva funcional de las construcciones suboracionales". Lingüística Española Actual 26.1 (2004): 71-109.

Díaz Hormigo, María Tadea. "Entre el léxico y la sintaxis: a propósito de la denominada sintaxis interna de las formaciones derivadas". Algunos problemas específicos de la descripción sintáctico-semántica. Eds. Juan Cuartero y Gerd Wotjak. Berlín: Frank \& Timme, 2005. 77-95.

Díaz Hormigo, María Tadea. "Puntos de contacto entre morfología, lexicología, semántica. Propuesta de delimitación”. Revista de Filología 28 (2010a): 165-79.

Díaz Hormigo, María Tadea. "Morfología y ciencias lingüísticas: a propósito de las relaciones entre morfología, lexicología, semántica". Tendencias en lingüística general y aplicada. Eds. Dolores García Padrón y María del Carmen Fumero Pérez. Frankfurt am Main: Peter Lang, 2010b. 81-95.

Espinosa García, Jacinto. Esquemas sintáctico-semánticos de la transitividad e intransitividad en español. Cádiz: Universidad de Cádiz, 1997.

Firbas, Jan. "On defining the theme in functional sentence analysis". Travaux Linguistiques de Prague 1 (1964): 267-80.

Hjelmslev, Louis. Principios de gramática general. 1928. Madrid: Gredos, 1976.

Laca, Brenda. Die Wortbildung als Grammatik des Wortschatzes. Untersuchungen zur spanischen Subjeknominalisierung. Tübingen: Gunter Narr, 1986.

Laca, Brenda. "Las nominalizaciones orientadas y los derivados españoles en -dor y -nte". La formación de palabras. Ed. Soledad Varela. Madrid: Taurus, 1993. 180-204.

Martinet, André. Elementos de lingüística general. 1960. 2. ed. Madrid: Gredos, 1978.

Martinet, André Estudios de sintaxis funcional. 1968. Madrid: Gredos, 1978. 
Morera, Marcial. "El Diccionario de familias de palabras de la lengua española: su componente morfológico". Morfología: Investigación, docencia, aplicaciones. Eds. José Carlos Martín Camacho y María Isabel Rodríguez Ponce. Cáceres: Universidad de Extremadura, 2007. 55-66.

Pena, Jesús. "Consideraciones en torno a la palabra y al morfema". Homenaxe ó Profesor Constantino García. Coords. Mercedes Brea y Francisco Fernández Rei. Santiago de Compostela: Universidade de Santiago de Compostela, 1991. 365-73.

Pottier, Bernard. Introduction à l'étude de morphosyntaxe espagnole. Paris: Ediciones Hispanoamericanas, 1964.

Pottier, Bernard. Presentación de la lingüistica. Fundamentos de una teoría. 1967. 2. ${ }^{a}$ ed. Madrid: Ediciones Alcalá, 1972.

Pottier, Bernard. Introduction à l'étude linguistique de l'espagnol. Paris: Ediciones Hispanoamericanas, 1972.

Roldán, Antonio. "Notas para el estudio del sustantivo". Problemas y principios del estructuralismo lingüístico. Madrid: CSIC, 1967. 71-87.

Real Academia Española. Diccionario de la lengua española. 23. a ed. Barcelona: Espasa Libros SLU. Edición electrónica, 2014.

Ries, John. Was ist Syntax? Ein kritischer Versuch. Marburg: Elwert, 1894.

Trnka, Bohumil. "Personal recollections of V. Mathesius and his circle". Theoretical Linguistics 10, 2/3 (1983): 249-52.

Trnka, Bohumil y otros. "Las Tesis de 1929". El círculo de Praga. Barcelona: Anagrama, 1980. 30-64.

Trubetzkoy, Nikolái Serguéievich. Principes de phonologie. Paris: Klincksieck, 1939.

Trujillo, Ramón. "Gramática, lexicología y semántica”. Revista Española de Linguiistica 2.1 (1972): 103-09.

Ullmann, Stephen. Semántica. Introducción a la ciencia del significado. 1962. Madrid: Aguilar, 1980. 